\title{
AMINO-SUBSTITUTED PORPHYRINS AT THE BORDER OF HYBRID MATERIALS GENERATION AND PLATINUM NANOPARTICLES DETECTION
}

\author{
DIANA ANGHEL ${ }^{a}$, MIHAELA BIRDEANU ${ }^{b}$, ANCA LASCU, \\ CAMELIA EPURAN ${ }^{\mathrm{a}}$, EUGENIA FAGADAR-COSMA ${ }^{\mathrm{a} *}$
}

\begin{abstract}
Two amino substituted porphyrins, namely: 5,10,15,20-tetrakis(4aminophenyl)porphyrin (TAPP) and 5,10,15,20-tetrapyridyl-21 H,23H-porphine (TPyP) have been used for complexation reaction of platinum nanoparticles (PtNPs) with the main purpose to recover or detect them from diluted leaching solutions, after transformation in colloidal solutions. The complexation reactions were monitored by UV-vis spectroscopy and revealed that both porphyrins have the capacity to complex PtNPs in different detection domains ranging from 2.776 to $40.457 \times 10^{-6} \mathrm{M}$ in the case of TAPP, and in a larger range of $8.07 \times 10^{-6}-$ $7.03 \times 10^{-5} \mathrm{M}$ in the case of TPyP. Excellent correlation coefficients of $99.35 \%$ and $99.57 \%$ respectively have been obtained in each case. During complexation a nanomaterial based on TAPP and a micromaterial composed from TPyP both having as second partner PtNPs were obtained and thoroughly characterized by atomic force microscopy (AFM). The aggregation phenomena that occurred for each amino-porphyrin in DMF, in their acidified solutions and in their hybrid materials, revealed that the TAPP-PtNPs hybrid is a nanomaterial, based on triangular prisms aggregates of acidulated TAPP, and the TPyPPtNPs hybrid is a micromaterial that is based on pyramidal shaped aggregated from the acidulated solution of TPyP.
\end{abstract}

Keywords: amino-substituted porphyrins, PtNPs, Pt-NPs detection, UV-vis spectroscopy, AFM characterization

\footnotetext{
a Institute of Chemistry "Coriolan Dragulescu", Mihai Viteazu Ave. 24, 300223 - Timisoara, Romania

${ }^{\mathrm{b}}$ National Institute for Research and Development in Electrochemistry and Condensed Matter, P. Andronescu Street 1, 300224- Timisoara, Romania

*Corresponding author: efagadar@yahoo.com
} 


\section{INTRODUCTION}

In the last few years, the chemistry of porphyrins and metalloporphyrins has received increased interest. The conjugated electron system of the tetrapyrrolic macrocycle leads to unique optical properties used in a large range of applications in: medicine (for photodynamic therapies) [1], analytical chemistry (molecular recognition) [2], catalysis (mediators in electrochemistry and in organic synthesis) [3, 4], artificial photosynthesis [5] and as photosensitizers for organic solar cells $[6,7,8]$ and in automotive industry [9].

This interest also covers the field of platinum nanoparticles due to the many uses of nanosized sensors [10, 11], catalysts [12] and drugs [13]. Platinum colloidal particles can be obtained by using different types of reduction agents [14], such as: trisodium citrate [15], aminodextrans [16], $\mathrm{NaBH} 4$, is used to initiate the reaction, forming small particles [17].

For instance, the synthesis in ethylene glycol applying UV-induced reduction offers both a higher stability and a lower size of the particles [18], 19]. The stabilization of colloidal particles is possible by encapsulation in polymers, such as: polyvinyl alcohol) (PVA), polyvinylpyrrolidone (PVP), polyacrylates, polyacrylamides, poly(ethylene glycol) (PEG) or by using surfactant agents, such as: cetyltrimethyl ammonium bromide (CTAB) that allow the formation of micelles [20, 21]. When stabilized with biocompatible polymers, like PVP, platinum nanoparticles have a beneficial effect upon the blood fluidity, under oxidative stress conditions [22].

The protective layer of the metal nanoparticles can be done also by covering them with different dyes that might improve the catalytic or sensitive properties of the colloids [23, 24]. Porphyrin molecules can perform this task with multiple benefits. For example, nanocomposites based on mesotetrakis(p-sulfonatophenyl)porphyrin and PtNPs are photocatalytically active for water reduction to produce hydrogen under UV-vis irradiation [25]. An efficient hydrogen reduction photocatalyst was obtained from PtNPs and Zn(II)-protoporphyrin IX as photosensitizer [26]. Photosensitizer nanocomposites, formed from platinum nanoparticles functionalized with multibranchedporphyrins are reported to generate donor-bridge-acceptor conjugates, thus facilitating the electron transfer [27].

The interest in recovery or detection of platinum is nowadays continuously increasing, as the natural resources are limited and the consumption as catalyst in various chemical reactions, especially in automotive industry, is very large. The best performance of $600 \mathrm{mg} / \mathrm{g}$ recovery imply biosorption of platinum using cellulose nano- fibers and nanocrystals modified with polyethylene imine [28]. Biomass materials [29], zeolites bearing hydrazine groups [30] or hybrids of oxalic acid [31] gave lower recovery performances of maximum $150 \mathrm{mg} / \mathrm{g}$. 
Other reported methods used in the last five years for platinum recovery are microwave-assisted with cloud point extraction [32], complexation [33-34] and ion exchange techniques, all from leaching solutions [35-37].

As most methods for the recovery of platinum that are economically feasible and environmentally friendly rely on adsorption phenomena, the purpose of our study was to design efficient materials based on porphyrins, capable to detect/recover PtNPs from leaching solution.

This novel approach relies on complexation phenomena between suitable porphyrins and platinum nanoparticles being both a facile method for the recovery of platinum from dilute solutions and a source of new platinum complexes.

Two amino-functionalized free-base porphyrins, an aliphatic one: 5,10,15,20-tetrakis(4-aminophenyl)porphyrin (TAPP) (Figure 1a) and an aromatic one: 5,10,15,20-tetrapyridyl-21H,23H-porphine (TPyP) (Figure 1b), were chosen to compare their distinctive abilities to recover platinum.

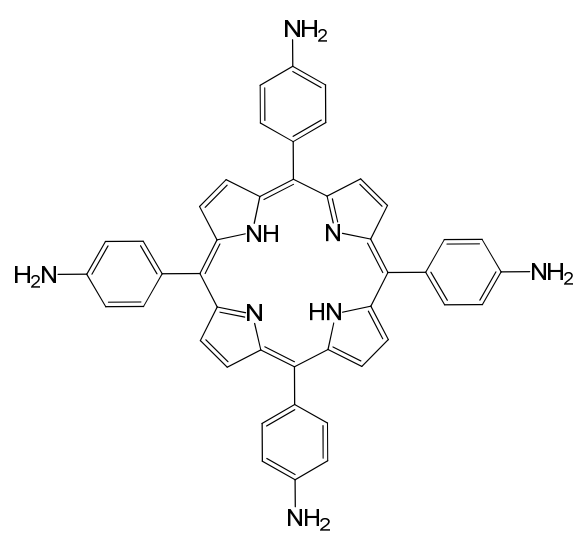

(a)

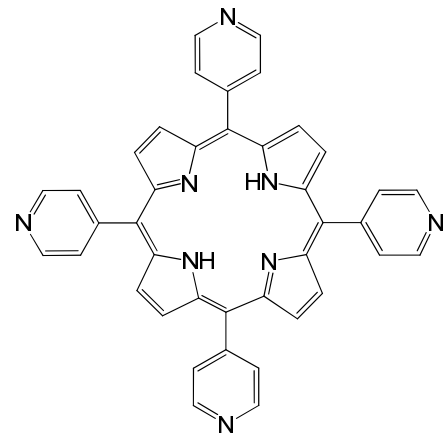

(b)

Figure 1. Structures of 5,10,15,20-tetrakis(4-aminophenyl)porphyrin (TAPP) (a) and 5,10,15,20-tetrapyridyl-21H,23H-porphine (TPyP) (b)

\section{RESULTS AND DISCUSSION}

\section{UV-vis spectroscopy of Pt-colloid and amino-porphyrins in DMF and in acid solutions}

The UV-vis spectra of Pt-colloid and amino-porphyrins both in DMF and in acid solutions are presented in Figure $2 \mathrm{~A}$ and $\mathrm{B}$. 


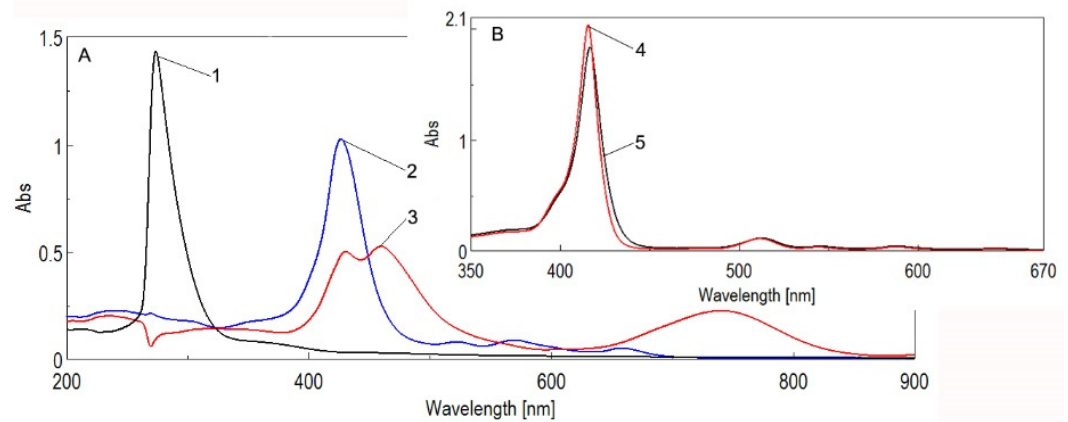

Figure 2. Overlapped UV-vis spectra of: Pt colloid in water (A1); TAPP in DMF $\left(\mathrm{c}=1.989 \times 10^{-5} \mathrm{M}\right)(\mathbf{A 2}) ;$ TAPP in acid environment $(\mathrm{pH}=2.5)(\mathbf{A} 3)$; TPyP in DMF

$\left(\mathrm{c}=8.834 \times 10^{-5} \mathrm{M}\right)(\mathrm{B} 4) ;$ TPyPin acid environment $(\mathrm{pH}=2.5)(\mathrm{B} 5)$

From Figure 2A-line 1, it can be observed that the maximum absorption peak for the platinum colloidal solution, located at $\lambda_{\max }=274 \mathrm{~nm}$, (figure $T$ line 1) does not belong to the visible region of the spectrum.

The TAPP porphyrin shows (Figure 2A-line 2), as expected, the intense Soret band at $426 \mathrm{~nm}$ accompanied by only three $\mathrm{Q}$ bands, located at: $522 \mathrm{~nm}$, $569 \mathrm{~nm}$ and respectively $658 \mathrm{~nm}$.

In the case of TAPP (Figure 2A-line 3), when reaching a $\mathrm{pH}=2.5$, after $\mathrm{HCl} 0.5 \mathrm{~N}$ solution was added, the splitting of the Soret band occurs due to the protonation of the two imino nitrogens from the inner structure of porphyrin. The deprotonation is accompanied by the disappearance of the Q2 and Q3 bands accompanied by both a significant hyperchromic effect and highly bathochromic shift of the Q1 band up to $740 \mathrm{~nm}$. All these aspects are indicative for an J-type aggregation process (side-by side arrangement of molecules) that is investigated further by AFM. Regarding TPyP (Figure 2Bline 4), at the same $\mathrm{pH}=2.5$, only a shift of the Soret band from $416 \mathrm{~nm}$ to 418 $\mathrm{nm}$ can be noticed, that might be the sign for a beginning of J-type aggregation.

\section{Platinum colloid detection}

2.1. Uv-vis monitoring of the complex generation between TAPP and PtNPs in acidulated medium

The complex generation between TAPP and PtNPs in acid medium was continuosly monitored by UV-vis spectroscopy (Figure 3).

By continuously adding of controlled amounts of PtNPs to the acidulated TAPP solution, a few complex phenomena took place. The first effect is the decrease in the intensity of the Soret band situated around 460 $\mathrm{nm}$ that is accompanied by a hypsochromic shift of around $5 \mathrm{~nm}$. 


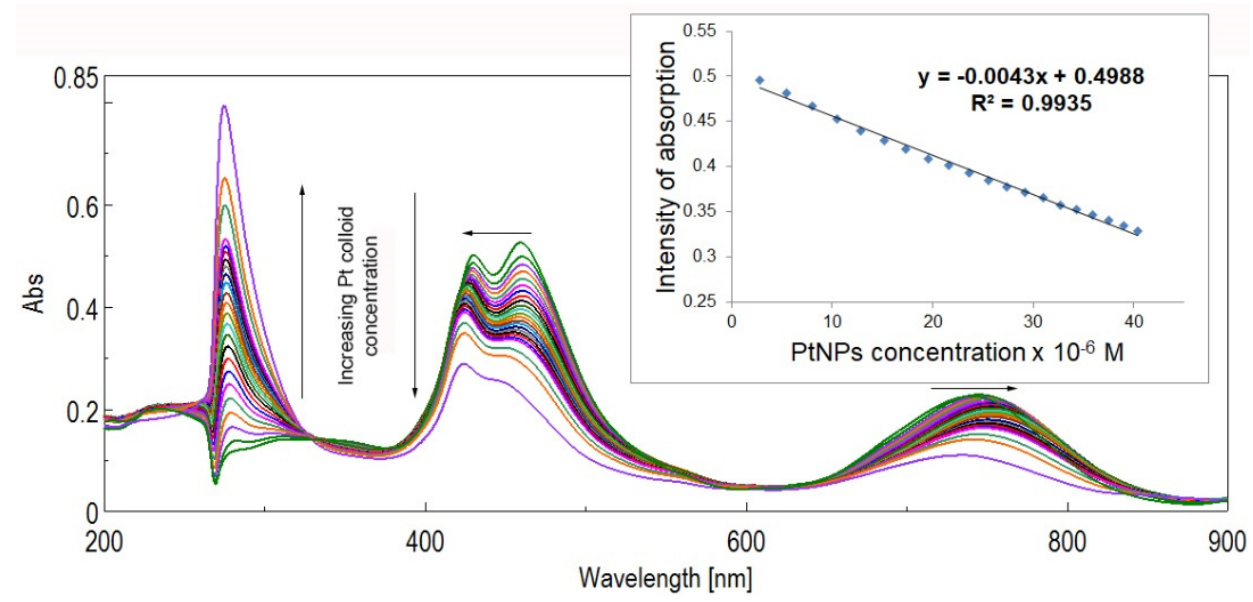

Figure 3. Overlapped UV-vis spectra monitoring the complex formation. In detail: linear dependence between the intensity of absorption of the hybrid Pt-TAPP read at $460 \mathrm{~nm}$ and PtNPs concentration

The same effect might be observed regarding the second Soret band initially located at $430 \mathrm{~nm}$ that is also blue shifted from 430 to $425 \mathrm{~nm}$.

A clear isosbestic point, located around $325 \mathrm{~nm}$, and another one at $630 \mathrm{~nm}$, indicate the formation of PtNPs-porphyrin complex, so that these optical effects cannot be explained by simple dilution.

The absorption maximum corresponding to the Pt plasmon is also hypsochromically shifted, from $274 \mathrm{~nm}$ to $276 \mathrm{~nm}$.

In the range of PtNPs concentrations from 2.776 to $40.457 \times 10^{-6} \mathrm{M}$ the dependence between the intensity of absorption of the plasmonic band read at $460 \mathrm{~nm}$ and the increasing concentration of PtNPs is linear, characterized by an excellent correlation coefficient of $99.35 \%$ (Figure 3-detail).

2. 2. Uv-vis monitoring of the complex generation between TPyP and PtNPs in acidulated medium

The successive adding of platinum colloid to the TPyP acidulated solution in DMF (c $=8.834 \times 10^{-5} \mathrm{M}$ ) leads to the formation of a complex nanomaterial, Pt-TPyP, evidenced by the presence of two isosbestic points, at $391 \mathrm{~nm}$ and $426 \mathrm{~nm}$ respectively, on both branches of the Soret band of the spectrum. A simple dillution phenomenon is excluded due to both the isosbestic points existence and because of the increasing in intensity of the $Q$ bands (Figure 4 and $A$ and $B$ details). 


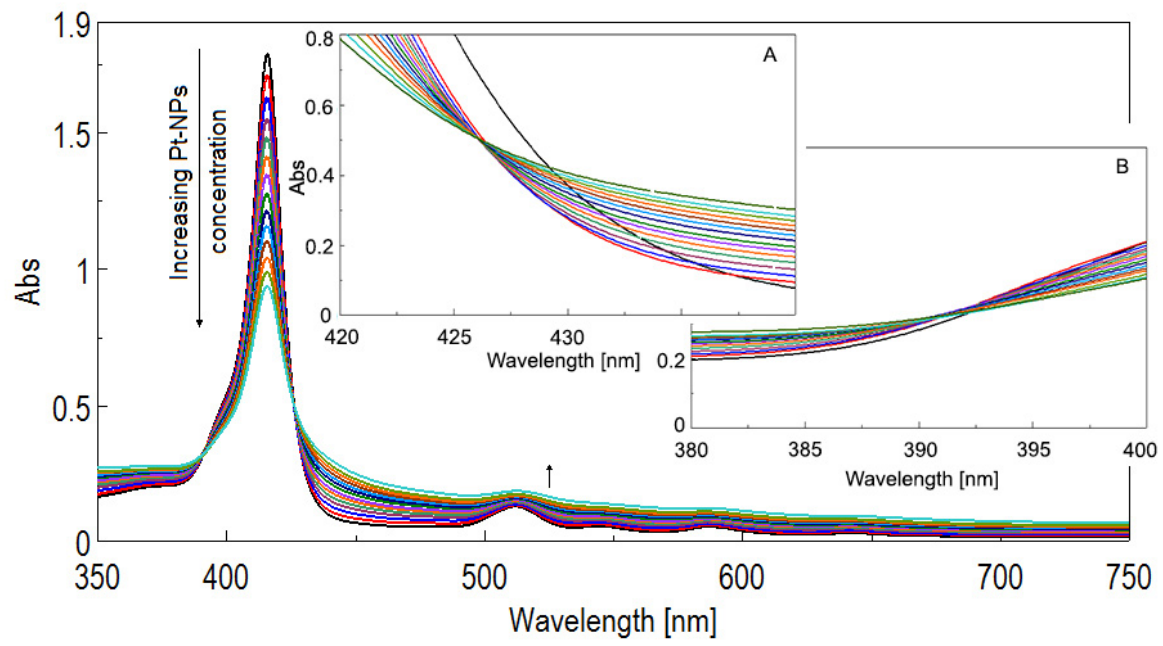

Figure 4. Overlapped UV-vis spectra after successive adding of of Pt-NPs solution to acidulated TPyP and isosbestic points detail: isosbestic point at $426 \mathrm{~nm}$ (A) and isosbestic point at $391 \mathrm{~nm}$ (B)

The dependence between the intensity of absorption of the Soret band read at $416 \mathrm{~nm}$ and PtNPs concentration is linear with an excellent corelation coefficient of $99.57 \%$ in the platinum concentration range: $8.07 \mathrm{x}$ $10^{-6}-7.03 \times 10^{-5} \mathrm{M}$, as represented in Figure 5 . These values are comparable to those detectable by TAPP porphyrin, proving that both porphyrins containing amino groups, either aliphatic or aromatic, are capable to form complexes with platinum nanoparticles.

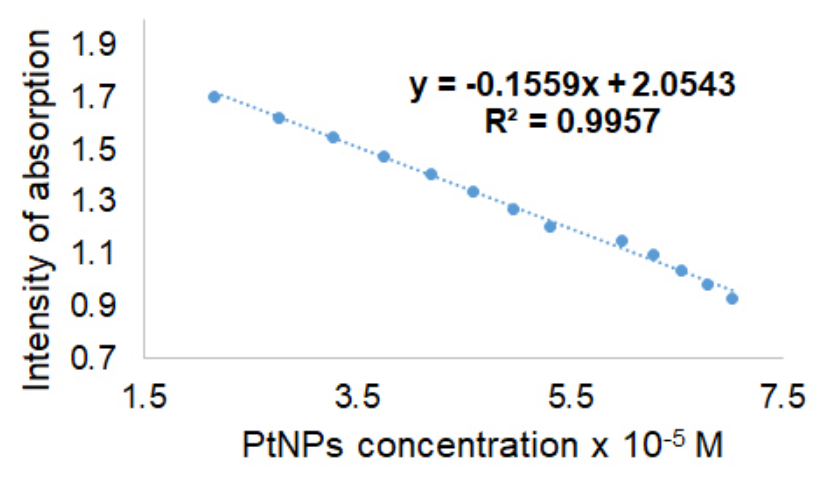

Figure 5. Linear dependence between the intensity of absorption of the Soret band read at $416 \mathrm{~nm}$ and PtNPs concentration 


\section{AFM investigation of the Pt colloid, bare porphyrins and hybrid nanomaterials}

Table $2(A, B, C)$ presents the main results from AFM investigation, regarding surface features, morphology and aggregation architectures.

Table $2 \mathrm{~A}$ reveals that the dimension of $\mathrm{Pt}$-colloid ovoid-like particles is varying in the range of $65-80 \mathrm{~nm}$ (Table $1 \mathrm{~A}$, $\mathrm{a}$ and $\mathrm{b}$ ) having the height distribution in the domain of $6-14 \mathrm{~nm}$. In the sized image of $4.59 \times 4.59 \mu \mathrm{m}$ the formation of some large platinum spherical shaped aggregates around $220 \mathrm{~nm}$ can be noticed, as expected from an unstabilized colloid.

Table 1A. AFM images of PtNPs $(a, b)$

\begin{tabular}{|c|c|c|}
\hline & Scanning $2.29 \times 2.29 \mu \mathrm{m}$ & Scanning $4.59 \times 4.59 \mu \mathrm{m}$ \\
\hline PtNPs & 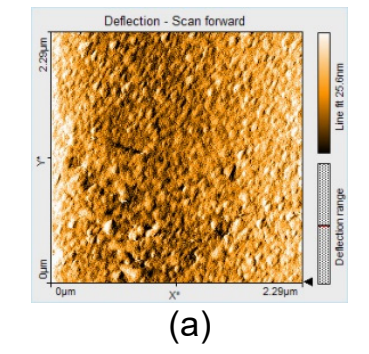 & 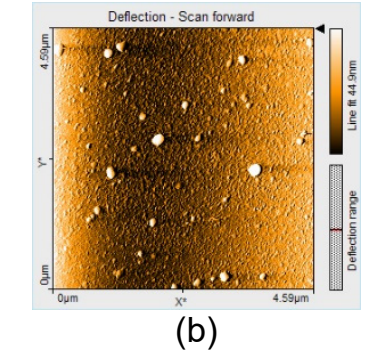 \\
\hline
\end{tabular}

The microscopy analysis was performed for TAPP porphyrin both solely and in acid $\mathrm{pH}$ medium. TAPP deposited by drop-casting from DMF on silica plates presents equilateral triangular building-block units (Table 1B, $C$ and $d$ ), with dimensions larger than those generated in acid medium (Table $2 \mathrm{~B}, \mathrm{e}, \mathrm{f})$, having the sizes around $165 \mathrm{~nm}$. The larger image $(4.59 \times 4.59 \mu \mathrm{m})$ puts into evidence besides the continuous covering of the surface with triangular architectures preserving the same orientation, a novel type of organization in bow-type wires, implying that both types of aggregation processes, an initial $\mathrm{H}$-type aggregation followed by the $\mathrm{J}$ - type phenomenon, are occurring.

Acidulated TAPP deposited on silica plates (Table 1B, e and f) presents the same orientation of triangular-shaped aggregates having sizes around $135 \mathrm{~nm}$. The height distribution is tighter, in the region from 2.2 to $5.3 \mathrm{~nm}$. In the 3-D image of acidulated TAPP (Table 1B, g) it can be seen triangular prisms randomly covering the surface and having the heights of $12 \mathrm{~nm}$. This aspect is a novelty, because the usual aggregation of porphyrins in acid media is in the pyramidal form [38]. 
Table 1B: AFM images of investigated compounds:TAPP (c, d); acidulated TAPP (e, f, g); TAPP-PtNPs hybrid (h, i)

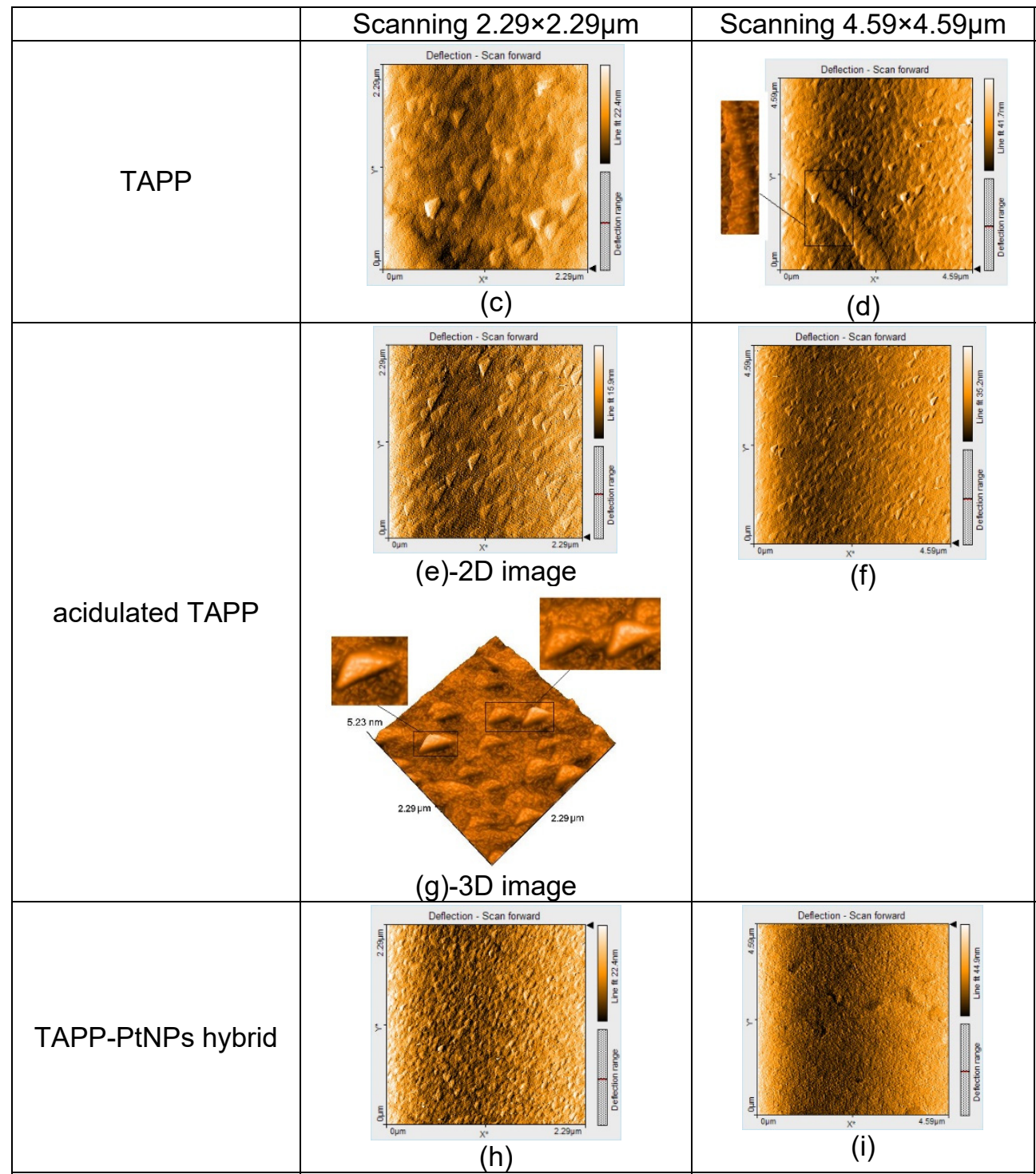

Regarding the rugosity, a comparison between the porphyrin-base in DMF and in acidulated DMF-water medium reveals that the acid surfaces have a smaller rugosity (Sa varying from $2 \mathrm{~nm}$ to $4.6 \mathrm{~nm}$ ) than those in DMF solution (Sa from $3 \mathrm{~nm}$ to $6.4 \mathrm{~nm}$ ). 
In the case of the hybrids obtained between porphyrin and Pt colloid (Table 1B, $\mathrm{h}$ and $\mathrm{i}$ ), the height distribution is smaller and narrower and the sizes are varying from 5 to $8.3 \mathrm{~nm}$. The hybrid nanomaterial has the whole structure reorganized showing smaller triangular particles with dimension of $35 \mathrm{~nm}$. In conclusion, the generation of complex between the TAPP and the PtNPs in acid media gave rise to a very well-structured nanomaterial, characterized by a slightly higher rugosity than that of TAPP in different media, that is around $3.2 \mathrm{~nm}$.

Regarding the pyridyl substituted derivative, TPyP, a roof type aggregation can be seen (Table $1 \mathrm{C}, \mathrm{j}$ and $\mathrm{k}$ ) at the interface DMF-air, generated by $\mathrm{H}$ - and $\mathrm{J}$-type processes using as building blocks triangular isosceles with dimensions of $122 \mathrm{~nm}$ and $204 \mathrm{~nm}$, respectively and height distribution in the range of $4-10 \mathrm{~nm}$.

Table 1C: AFM images of the investigated compounds: TPyP $(j, k)$; acidulated $\operatorname{TPyP}(\mathrm{l}, \mathrm{m}) ;$ TPyP-PtNPs hybrid $(\mathrm{n}, \mathrm{o})$

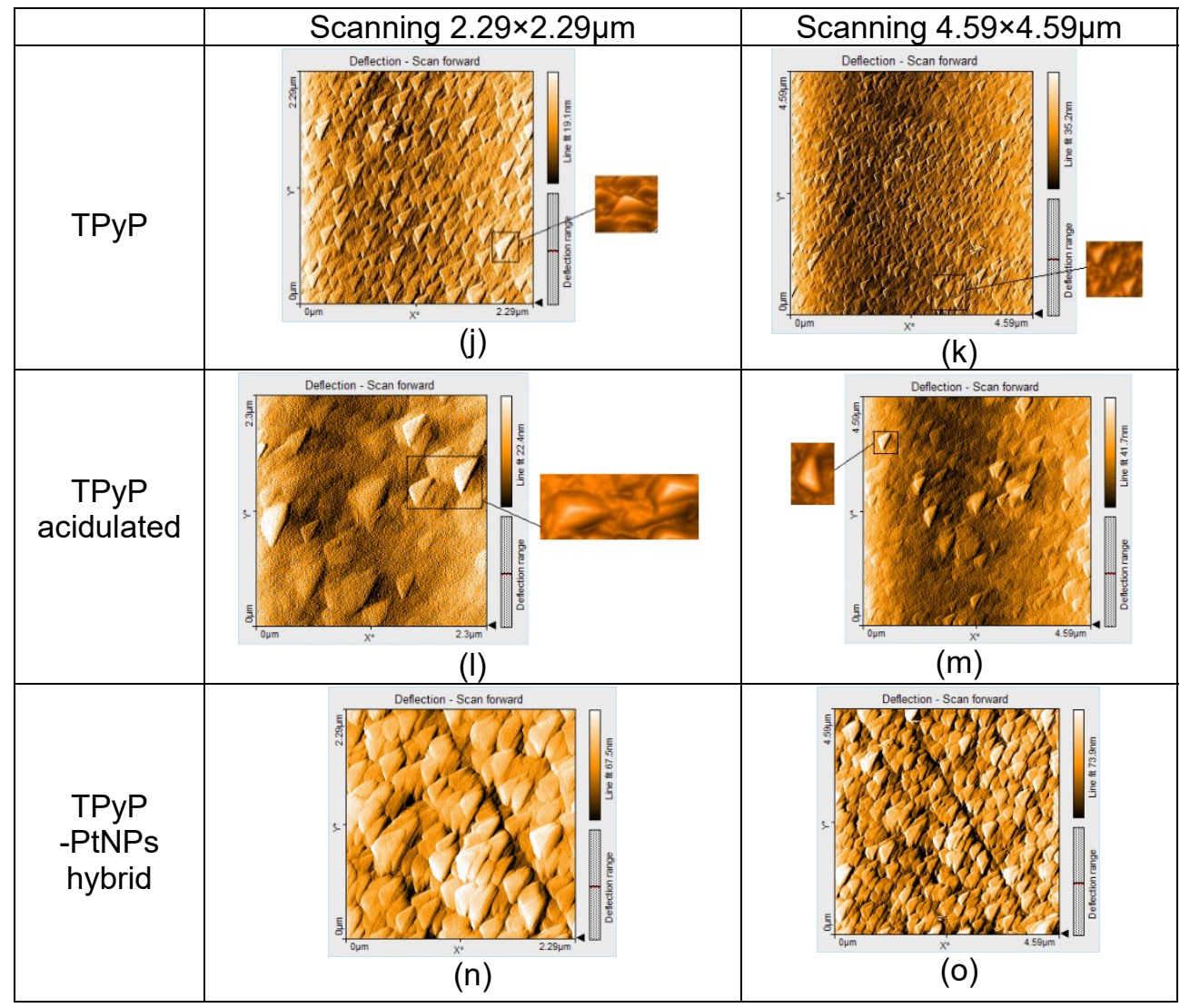


When the TPyP is deposited from DMF acid medium (Table 1C, I and $\mathrm{m}$ ), the rugosity is increasing, this aspect being divergent with the behavior of TAPP.

In the 3-D images (Table 1C, I-detail), the architecture of the aggregates is a pyramidal one, that is another different aspect as compared to TAPP.

The hybrid micromaterial, TPyP-PtNPs (Table 1C, $\mathrm{n}$ and o) has the surface morphology constituted from equilateral triangles having dimensions of around $320-450 \mathrm{~nm}$, that are amazingly organized as the bricks in a wall (generated by sandwich-type aggregation) and showing distinct rows (generated by J-type aggregation).

The height distribution is in this particular case larger, in the range of 22 - $70 \mathrm{~nm}$.

\section{The recovery of PtNPs}

The recovery of PtNPs was performed as previously reported [34] by precipitating PtNPs from the two obtained hybrid materials using $1 \mathrm{~N} \mathrm{HCl}$ solution (Figure 6A).

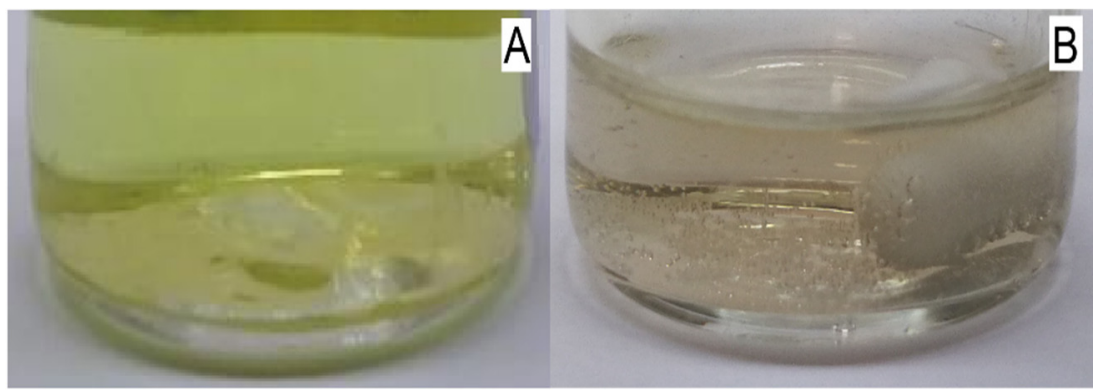

Figure 6. Reduction of the PtNPs-porphyrin complexes using $1 \mathrm{~N} \mathrm{HCl}(\mathrm{A})$ and $\mathrm{NaBH}_{4}(\mathrm{~B})$

The recovery efficiency of these two aminoporphyrins was evaluated from the capacity of complexation and the results are promising: $602 \mathrm{mg} \mathrm{Pt} / \mathrm{g}$ TAPP and $212 \mathrm{mg} \mathrm{Pt} / \mathrm{g}$ TPyP, corresponding to approximately 3 mole PtNPs/ 1 mole TAPP and 1 mole PtNPs/ 1 mole TPyP. A plausible explanation might be that TAPP is capturing PtNPs in the inner part of the molecule and also between the $-\mathrm{NH}_{2}$ functional groups (from 5,10 and 15, 20) but the TPyP creates coordinative bonds only in the center of the molecule. 


\section{CONCLUSIONS}

The design of efficient materials based on different amino-substituted porphyrins, capable to detect or recover PtNPs from leaching solution was the main aim of this study.

This novel approach relies on complexation phenomena between suitable porphyrins and platinum nanoparticles being both a facile method for the recovery of platinum from dilute solutions and a source of new platinum complexes.

Two amino-functionalized free-base porphyrins, an aliphatic one: 5,10,15,20-tetrakis (4-aminophenyl)porphyrin (TAPP) and an aromatic one: $5,10,15,20$-tetrapyridyl-21 $\mathrm{H}, 23 \mathrm{H}$-porphine (TPyP) were chosen to compare their distinctive abilities to recover platinum. The platinum from the synthetic leaching solution containing $\mathrm{H}_{2} \mathrm{PtCl}_{6} \times 6 \mathrm{H}_{2} \mathrm{O}$ was transformed in colloidal $\mathrm{Pt}$ by reducing with $\mathrm{NaBH}_{4}$.

The complexation reactions were monitored by UV-vis spectroscopy and revealed that each of these porphyrins have the capacity to complex PtNPs in different detection domains ranging from 2.776 to $40.457 \times 10-6 \mathrm{M}$ in the case of TAPP, and in a larger range of $8.07 \times 10-6-7.03 \times 10-5 \mathrm{M}$ in the case of TPyP. Excellent correlation coefficients of $99.35 \%$ and 99.57 respectively have been obtained in each case.

During complexation a nanomaterial based on TAPP and a micromaterial composed from TPyP both having as second partner PtNPs were obtained and thoroughly characterized by AFM. The aggregation phenomena that occurred for each amino-porphyrin in DMF, in their acidified solutions and in their hybrid materials, revealed that the TAPP-PtNPs hybrid is a nanomaterial, and the TPyP-PtNPs hybrid is a micromaterial. Both hybrid materials have as building block units TAPP or TPyP already aggregated in triangular geometries of different sizes (with two or all three sides equal), but always uniformly oriented.

The recovery efficiency of these two aminoporphyrins was evaluated from the capacity of complexation and the results are promising: $602 \mathrm{mg} \mathrm{Pt}$ /g TAPP and $212 \mathrm{mg} \mathrm{Pt} / \mathrm{g}$ TPyP, corresponding to approximately 3 moles PtNPs/ 1 mole TAPP and 1 mole PtNPs/ 1 mole TPyP.

\section{EXPERIMENTAL SECTION}

\section{Reagents}

Hexachloroplatinic acid and trisodium citrate were purchased from Sigma-Aldrich (St. Louis, USA). Sodium borohydride was provided by Merck (Darmstadt, Germany) and doubly distilled water was used for all experiments. 
The synthesis of TAPP was done in two steps involving the obtaining of 5,10,15,20-meso -tetrakis-(p-nitrophenyl) porphyrin, followed by the reduction of nitro-groups with $\mathrm{SnCl}_{2} \times 2 \mathrm{H}_{2} \mathrm{O}$ [39].

The synthesis of TPyP was done in accordance with published results [40] starting from 4-pyridinecarboxaldehyde and pyrrole in propionic acid.

\section{Synthesis of the platinum colloid}

In order to check the viability of PtNPs complexation and its total recovery after the reduction of complexes, we used for the platinum colloid generation $\mathrm{H}_{2} \mathrm{PtCl}_{6} \times 6 \mathrm{H}_{2} \mathrm{O}$, thus creating an ideal situation. In real leaching solutions, a mixture of valuable metal ions, such as: $\mathrm{Pt}$ (in the form of $\left.\left(\mathrm{NH}_{4}\right)_{2} \mathrm{PtCl}_{6}\right), \mathrm{Pd}$ and $\mathrm{Rh}$ are present, besides $\mathrm{Ni}$ and $\mathrm{Mn}$ ions that are not interfering.

So, the platinum colloid was synthesized after previously reported data [41], as follows: a solution was prepared from $0.01697 \mathrm{~g}\left(3.276 \times 10^{-5}\right.$ mole) of $\mathrm{H}_{2} \mathrm{PtCl}_{6} \times 6 \mathrm{H}_{2} \mathrm{O}$ dissolved in $77.9 \mathrm{~mL}$ distilled water with molar concentration of $\mathrm{c}=1.416 \times 10^{-4} \mathrm{M}$. To this solution $2 \mathrm{~mL}$ trisodium citrate with $\mathrm{c}=0.04 \mathrm{M}$ were added and stirred for 30 minutes at room temperature. After 30 minutes of vigorous stirring $0.409 \mathrm{~mL} \mathrm{NaBH}{ }_{4}$ solution with concentration $0.05 \mathrm{M}$, was added dropwise. The mixture was stirred and allowed to react at ambient temperature for $1 \mathrm{~h}$.

The solution color changed from yellowish to brownish yellow due to optical phenomena associated to the formation of nanometric particles [42].

\section{Obtaining the TAPP-Pt-colloid complex}

To a volume of $5 \mathrm{~mL}$ TAPP in DMF $\left(c=1.808 \times 10^{-5} \mathrm{M}\right) 0.1 \mathrm{~mL}$ portions of $\mathrm{Pt}$ colloid solution $\left(\mathrm{c}=1.416 \times 10^{-4} \mathrm{M}\right.$ ) in water were added. The mixture was stirred for 30 seconds and then the UV-vis spectra were recorded and overlapped (as shown in Figure 3).

\section{Obtaining the TPyP-Pt-colloid complex}

The experiment was done in a similar way, changing only the concentration of TPyP solution in DMF $\left(c=8.834 \times 10^{-5} \mathrm{M}\right)$. The overlapped UV-vis spectra were registered (as shown in Figure 4).

\section{Method for the recovery of PtNPs}

The two obtained complexes PtNPs-TAPP and PtNPs-TPyP were subjected to a reduction reaction using $1 \mathrm{~N} \mathrm{HCl}$ and $\mathrm{NaBH}_{4}$ solutions and it was clearly proven that the platinum nanoparticles were precipitated. 
AMINO-SUBSTITUTED PORPHYRINS AT THE BORDER OF HYBRID MATERIALS GENERATION AND PLATINUM NANOPARTICLES DETECTION

\section{Apparatus}

For recording UV-visible spectra a V-650 - JASCO spectrometer (Pfungstadt, Germany) having $1 \mathrm{~cm}$ wide quartz cuvettes was used. Atomic force microscopy (AFM) images were obtained on a Nanosurf®EasyScan 2 Advanced Research AFM microscope (Liestal, Switzerland). The samples were deposited on pure silica plates by drop casting from DMF solution.

\section{ACKNOWLEDGMENTS}

This research is funded by UEFISCDI, project ECOTECH-GMP 76 PCCDI/2018, belonging to PNIII-Future and Emerging Technologies and partially by Romanian Academy through Programme 3/2020 from Institute of Chemistry "Coriolan Dragulescu".

\section{REFERENCES}

1. J. Kou; D. Dou; L. Yang; Oncotarget, 2017, 8(46), 81591-81603.

2. J.S. Rebouças; B.R. James; Inorg Chem., 2013, 52(2), 1084-1098.

3. M.R. Civic; P.H. Dinolfo; ACS Appl. Mater. Interfaces, 2016, 8(31), 2046520473.

4. J. Barona-Castaño; C. Carmona-Vargas; T. Brocksom; K. de Oliveira; Molecules, 2016, 21(3), 310.

5. G. Bottari; O. Trukhina; M. Ince; T. Torres; Coord. Chem. Rev., 2012, 256(2122), 2453-2477.

6. X. Qian; L. Lu; Y.-Z. Zhu; H.-H. Gao; J.-Y. Zheng; RSC Advances, 2016, 6(11), 9057-9065.

7. O. Rezazgui; G. Marchand; P. Trouillas; B. Siegler; S. Leroy-Lhez; Chemistry Select, 2018, 3(39),10959-10970.

8. X. Sun; G. Chen; J. Zhang; Dyes Pigm., 2008, 76(2), 499-501.

9. C. Liu; S.C. Sun; X.P. Zhu; G.F. Tu; J.Y. Zhang; IOP Conf. Series: Materials Science and Engineering, 2019, 479, 012058.

10. G.V. Fedorenko; L.P. Oleksenko; N.P. Maksymovych; I.P. Matushko; Russ. J. Phys. Chem. A, 2015, 89(12), 2259-2262.

11. E. Fagadar-Cosma; I. Sebarchievici; A. Lascu; I. Creanga; A. Palade; M. Birdeanu; B. Taranu; G. Fagadar-Cosma; J. Alloys Compd., 2016, 686, 896-904.

12. C.A. Mak; M.A. Pericas; E. Fagadar-Cosma; Catal. Today, 2018, 306, 268-275.

13. T.C. Johnstone; K. Suntharalingam; S.J. Lippard; Chem. Rev., 2016, 116(5), 3436-3486.

14. A.L. Stepanov; A.N. Golubev; S.I. Nikitin; Y.N. Osin; Rev. Adv. Mater. Sci., 2014, 38, 160-175

15. A.S. Dehnavi; A. Raisi; A. Aroujalian; Synth. React. Inorg. Met.-Org. Nano-Metal Chem., 2013, 43(5), 543-551.

16. L. Dykman; A. Lyakhov; V.A. Bogatyrev; S. Shchyogolev; November Colloid Journal, 1998, 60(6), 700-704.

17. A. Martínez-Abad; Multifunctional and Nanoreinforced Polymers for Food Packaging, 2011, 347-367. 
18. L. Kacenauskaite; J. Quinson; H. Schultz; J.J.K. Kirkensgaard; S. Kunz; T. Vosch; M. Arenz; Chem Nano Mat, 2016, 3(2), 89-93.

19. J. Quinson; M. Inaba; S. Neumann; A.A. Swane; J. Bucher; S.B. Simonsen; L.T. Kuhn; J.J.K. Kirkensgaard; K.M.O. Jensen; M. Oezaslan; S. Kunz; M. Arenz; ACS Catalysis, 2018, 8(7), 6627-6635.

20. T.M. Tolaymat; A.M. El Badawy; A. Genaidy; K.G. Scheckel; T.P. Luxton; M. Suidan; Sci Total Environ., 2010, 408(5), 999-1006.

21. L.S. Nair; C.T. Laurencin; Prog. Polym. Sci., 2007, 32(8-9), 762-798.

22. S. Kato; R. Hokama; H. Okayasu; Y. Saitoh; K. Iwai; N. Miwa; JNN, 2012, 12(5), 4019-4027.

23. X. Wang; P. Sonström; D. Arndt; J. Stöver; V. Zielasek; H. Borchert; K. Thiel; K. Al-Shamery; M. Bäumer; J. Catal. 2011, 278(1), 143-152.

24. D.A. Gregory; S.J. Ebbens; Langmuir, 2018, 34(14), 4307-4313.

25. L. Zhang; Y. Lu; Y. Du; P. Yang; X. Wang; J Porphyr Phthalocya, 2010, 14(06), 540-546.

26. E.R. Clark; D.M. Kurtz; Inorg. Chem., 2017, 56(8), 4584-4593.

27. K. Ladomenou; M. Natali; E. lengo; G. Charalampidis; F. Scandola; A.G. Coutsolelos; Coord. Chem. Rev., 2015, 304-305, 38-54.

28. H.-J. Hong; H. Yu; M. Park; H.S. Jeong; Carbohydr. Polym., 2019, 210, 167-174.

29. D.J. Garole; B.C. Choudhary; D. Paul; A.U. Borse; Environ Sci Pollut Res, 2018, 25(11), 10911-10925.

30. A.K. Mosai; L. Chimuka; E.M. Cukrowska; I.A. Kotzé; H. Tutu; Miner. Eng., 2019, 131, 304-312.

31. H. Malekian; M. Salehi; D. Biria; Waste Manag., 2019, 85, 264-271.

32. T. Suoranta; O. Zugazua; M. Niemelä; P. Perämäki; Hydrometallurgy, 2015, 154, 56-62.

33. D. Anghel, I. Frațilescu, A. Lascu; New trends and strategies in the chemistry of advanced materials with relevance in biological systems, technique and environmental protection, 2019, 6-7.

34. A. Lascu; Proceedings of the 25thInternational Symposium on Analytical and Environmental Problems, 2019, 18-22.

35. M.S. Safarzadeh; M. Horton; A.D. Van Rythoven; Min Proc Ext Met Rev, 2017, 39(1), 1-17.

36. Y. Ding; H. Zheng; J. Li; S. Zhang; B. Liu; C. Ekberg; Z. Jian; Metals, 2019, 9(3), 354.

37. A.N. Nikoloski; K.L. Ang; D. Li; Hydrometallurgy, 2015, 152, 20-32.

38. E. Fagadar-Cosma; G. Fagadar-Cosma; M. Vasile; C. Enache; Curr. Org. Chem., 2012, 16, 931-941

39. A. Bettelheim; B.A. White; S.A. Raybuck; R.W. Murray; Inorg. Chem., 1987, 26, 1009-1017.

40. E. Fagadar-Cosma; C. Enache; I. Armeanu; G. Fagadar-Cosma; Dig. J. Nanomater. Bios., 2007, 2, 175 - 183.

41. G.W. Wu; S.B. He; H.P. Peng; H.H. Deng; A.L. Liu; X.H. Lin; X.H. Xia; W. Chen; Anal. Chem., 2014, 86(21), 10955-10960.

42. B. Escobar Morales; S.A. Gamboa; U. Pal; R. Guardián; D. Acosta; C. Magaña; X. Mathew; Int. J. Hydrog. Energy, 2010, 35(9), 4215-4221. 